Este trabalho busca pensar a tensão inerente à ação educativa em seu aspecto formal, praticada pela escola, e no informal, ministrada pela familia, levantando alguns pontos de impossibilidade que vêm se transformando em impotencia e conseqüente fracasso da educaçào. O fracasso escolar, considerado uma das patologias de nosso tempo, vem sendo associado à manipulação das promessas de gozo inerentes às açòes politicas da educação amparadas por uma ética da globalização e da queda de ideais. Estas questōes interrogam o psicanalista na interseção psicanálise e educação.

Psicanálise; educação; fracasso escolar; ética e política

THE PSYCHOANALYST ROLE AT SCHOOL

In this work we analyze the tension inherent to the educative action in its formal aspect, practiced at school, and in its informal aspect, practiced by the family, raising some questions of impossibility that give rise to impotence and as a consequence the miscarriage of education. The miscarriage of school, considered one of the pithologies of our time, is being associated to the manipulation of the promises of pleasure associated to the political actions of Education, supported by an ethic of globdlization and by the loss of ideals. These are questions that are brought to the psycloonalyst in intersection of the psychounalysis and education. Psychoanalysis; education; miscarriage of education; ethic and policy

\section{O LUGAR DO PSICANALISTA NA ESCOLA}

\author{
Ruth Helena Pinto Cohen \\ Cristiane Fiaux Lessa \\ Daisy Christine Melo \\ Gisella Cohen \\ Márcia Denise Dutra Sias \\ Oziléia Glen Gomes Serafim \\ Rachel Tinoco Marinho Alves \\ Rodrigo Abecassis
}

"I osto de dar aula, da minha profissão. Só que eu me sinto angustiada por não estar conseguindo desenvolver um trabalho como eu gostaria."

"Para conseguirmos trabalhar, abrimos um espaço extra-oficial de trocas entre os professores. Falamos de nossos problemas e de nossas angústias."

Coordenadora do Projeto Aleph, psicanalista, membro aderente da EBP-RJ, mestre em Psicologia pela UFRJ, doutoranda pela UFRJ.

- Psicanalista, pós-graduada em Psicopedagogia, formação na SPAG-RJ $\left({ }^{*}\right)$.

口ם Psicanalista $\left({ }^{*}\right)$.

口ם Psicóloga pela PUC-RJ, pós-graduada em Psicologia Clínica na Santa Casa de Misericórdia do Rio de Janeiro (*).

口曰-1 Psicanalista, psicóloga do Instituto Metodista Bennett, com formação em Psicopedagogia e dependência química $\left({ }^{*}\right)$.

1010 Psicanalista da Escola Lacaniana de Psicanálise do Rio de Janeiro, com formação em dependência química (*).

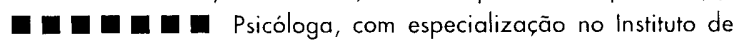
Psiquiatria da UFRJ (IPUB) (*).

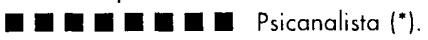
(*) Pesquisadores do Projeto Aleph. 
"Não sei onde está o ' $x$ ' da questão. Como despertar o interesse dos alunos?"

"É preciso colocar a responsabilidade na família, porque ela acha que a gente tem de assumir tudo. A família está cada vez com menos compromisso, e a escola assumindo tudo."'

$O$ presente artigo apresenta aspectos de uma pesquisa de campo e intervenção na cidade do Rio de Janeiro que vem sendo desenvolvida pelo Projeto Aleph, vinculado à ONG Entrelaces - Psicanálise e Educação.

A intenção do referido projeto é refletir sobre questões propostas nas áreas de psicanálise e educação, com ênfase no fracasso escolar, interrogando-se a partir de quatro dimensões: a primeira traça uma leitura das especificidades da história de crianças e adolescentes, alunos que não conseguem ser alfabetizados; a segunda interroga a queixa permanente e o alto nível de angústia dos professores e o impacto que esta questão lhes causa; a terceira refere-se à ética e à política vigentes na educação em sua interseção com a psicanálise; e a quarta dimensão está ligada a lugar que o psicanalista pode ocupar na escola. A ênfase maior está na última dimensão, apenas tangenciando os outros temas. O propósito é fornecer dentro do possível uma visada sobre algumas questões que instigam os psicanalistas a um trabalho de psicanálise em extensão.

A primeira questão com que o perquisador se defronta no trabalho em campo nessa área inclui uma interrogação sobre quem são essas crianças e adolescentes que fracassam. Por que o fracasso escolar, apesar dos esforços de inúmeros projetos educacionais, não cessa de se escrever (Lacan, 1972-3, p. 127) como um sintoma social necessário?

Dentro do contexto da tecnociência e tendo como pano de fundo o neocapitalismo, busca-se enfatizar a articulação entre tensões que se impõem ao sujeito do inconsciente e aos processos educativos. O campo da cultura, apontado por Freud em sua dissonância em relação às exigências pulsionais, evidencia que o campo do Outro da Educação - se encontra disjunto com o campo do $U m$, confirmando a tese lacaniana da não completude, da impossibilidade intrínseca à educação, ou seja, a "não relação".

Freud, ao pensar a educação, não preconizou a erradicação do "mal" pulsional como uma saída, mas apontou caminhos indicando algumas possibilidades para a educação necessária. Dizia ele: "A criança deve aprender a controlar suas pulsões. É impossível conceder-lhe liberdade de pôr em prática todos os seus impulsos sem restrição" (Freud, 1932-3, p. 167). Neste caso, a educação necessária talvez pudesse ser verificada a meio caminho da não interferência e da frustração. Outra preocupação freudiana adverte sobre a impossibilidade 
de um mesmo método educativo poder ser uniformemente bom para todas as crianças. É exatamente neste rastro que se procura encaminhar a questão do Projeto Aleph, indo em direção a uma pesquisa sobre as políticas educacionais da atualidade, com seus novos métodos educativos, que tentam combater o fenômeno do fracasso escolar na cidade do Rio de Janeiro.

Ao abordar um sintoma social o fracasso escolar -, indicam-se as modalidades de inscrição dadas pelo "Outro" da educação às crianças e adolescentes na atualidade. Esse "Outro" não vem garantindo de forma consistente o coletivo e os ideais, mas porta um modo de gozo específico que Lacan localizou no conceito de objeto pequeno “a”. No caso do fracasso escolar, esse gozo "a mais" pode se produzir, entre outros fatores, por um excesso de saber e pelo consumo de novas tecnologias educacionais, muitas vezes ineficazes.

Uma outra vertente, que parece corroborar a exacerbação do fracasso escolar, advém da política de globalização, que trouxe inúmeras conseqüências ao ato de educar. Observa-se que o problema também se estende a outros países, como se pode verificar na seguinte declaração: "Roubar, furtar representam o prazer rápido", como caracterizou o diário Berlin Tageszeitung, de forma mordaz, o estilo de vida da geração jovem. "O concorrente está à espreita em todo canto." E, continuando: "Os pais negligenciam a educação, declara o presidente do Congresso, o deputado social-democrata Wilfried Penner, mas milhões de pais contra-argumentam: quanto tempo ainda sobra para a educação aos pais que precisam trabalhar, completamente estressados ..." (Martin \& Shumann, 1997, p. 238).

Diante desse impossivel que é o ato de educar, os analistas vêm buscando a rede dos discursos da psicanálise e da educação, em um profícuo trabalho de interseção. Acreditase que o tecido - produto do entrelaçamento desses fios - poderá dar à psicanálise uma certa pontuação e à educação, uma nova vertente de reflexão. As ações do psicanalista e do educador, na cidade, pela experiência da transmissão de saber, interferem e trazem conseqüências a seus atos a partir dos "nós" da educação, muitas vezes chamados de "nós cegos".

$\mathrm{O}$ ato analítico, assim como o ato educativo com seus saberes e ações diferenciadas, vem encontrando na visada política e ética novos paradigmas que norteiam os laços, que regem a família e a escola na contemporaneidade. $O$ relato de alguns analistas que trabalham no Projeto Aleph indicam como estão sendo vivenciadas as mensagens contraditórias da educação na atualidade.

Depoimentos de psicanalistas confirmam a existência de paradoxos, que vão desde o espaço físico de uma escola até a didática aplicada em sala de aula:

"Pensar sobre a experiência na escola A nos remete a relacioná-la, num âmbito maior, ao contexto em que está inserida. Esta escola situada em uma favela tem à sua volta os bairros mais nobres da cidade. Uma paisagem paradoxal, que ao mesmo tempo faz parte de nossa cultura rica por sua diversidade". 
"A professora $Z$ diz que está no magistério há muitos anos e se coloca como acostumada com crianças problemáticas. Faz alusão à desestruturação familiar na maioria das crianças. Os mais carentes não tền a figura de mãe, é a avó geralmente que cuida, e do pai normalmente nada se sabe."

Seria possível localizar nesse último relato as dificuldades com o exercício das funções materna e paterna na contemporaneidade? A função paterna, necessária à educação e cada vez mais inconsistente, tem deixando os filhos do Estado capitalista sob a égide de uma crise de legitimidade. Como anda a lei que rege a educação? Não seria o advento explosivo da barbárie conseqüência da perda de força educadora da palavra? A palavra vem perdendo sua potência; por não ser mais o maior veículo do laço social, vem trazendo sérias conseqüências à transmissão do saber.

Uma Sociedade em que a Lei não garante o direito dos homens é um corpo social psicotizado, produtor de situações em que alguns gozam, usufruem "corpos-objetos" submetidos aos caprichos daqueles que conduzem uma determinada sociedade. A rede discursiva criada por laços sociais sob os quais seres humanos estão presos ou conectados faz deles corpos virtuais, em que quase tudo pode ser resolvido pela máquina: empresas, negócios, amizades, sexo, reuniões, trabalho, compras, isto tudo sem sair de casa. Tem-se como promessa o assalto ou a morte. As prisões, domiciliar e escolar, cada vez mais enclau- suram o sujeito em condomínios e muros, que se erguem mais fortes que os dos antigos asilos para. loucos, numa tentativa de barrar o gozo, o a mais transbordante.

Quando se escuta o responsável pela política educacional de cada escola - o diretor -, testemunha-se a seguinte situação: "Muitas vezes somos reféns do tráfico de drogas e da nova ordem perversa das favelas”. Este fato coabita com a apatia e a indiferença dos alunos em face do próprio fracasso escolar. Parece que se está diante de um tipo de gozo, em que o Outro encontra-se excluído. Talvez se possa identificar aí a dimensão autista do sintoma (Miller \& Laurent, 1997, p. 27-8).

Supõe-se que, semelhantes aos drogados, alguns alunos com fracasso escolar parecem anestesiados, "fora do ar", no campo irrespondivel da demanda, garantindo assim uma certa autonomia, um "quero saber nada". Seria esta uma tentativa de separação com o Outro da educação?

O depoimento de um aluno de uma classe de Aceleração de Aprendizagem sobre a rotatividade dos professores é ilustrativo: "Ninguém quer ficar com a gente, não é, tia?" Sua turma estava passando pelo quinto professor, pois todos adoeciam. Diante deste quadro, depara-se com a imagem do professor angustiado por se sentir impotente diante da tarefa de ensinar. A suposição ao saber no mestre contemporâneo encontra-se imbricada a um suposto se angustiar. Assim, o fracasso escolar, entre os novos sintomas, parece ocorrer também quando um excesso, um transbordamento de angústia empurra o 
professor para fora da sala de aula. A evasão agora é da mestria.

Reforçando esse aspecto, o depoimento de um professor delimita como é difícil a interseção psicanálise/educação:

"Consigo localizar claramente os problemas orgânicos, neurológicos e os socioeconômicos, estes últimos são 'carências materiais'. A escola não consegue dar conta é de suprir as funções da família”.

Seria essa a função da escola? Pode-se inferir que a crescente predominância do discurso da histérica, segundo Lacan, revela o pai como um mestre castrado, e a impotência deste como representante da Lei cria um estado compativel com o que Jacques-Alain Miller chamou de psicose ordinária, para apontar que se vive em uma época que ninguém tem mais habilidade para gerenciar (Miller, 1999). O crescente fracasso escolar, como um sintoma contemporâneo, denuncia a existência de uma educação baseada em suposta igualdade entre homens e mulheres, entre adultos e crianças igualados como sujeitos consumidores. Como conseqüência, tem-se a difusão, na cultura, de uma promessa de gozo, em que quase tudo é permitido. Que economia psíquica faz com que se pague qualquer preço pelo prazer e se busque "cada vez um a mais", mesmo que ao preço da dor ou da morte? Não teria a banalização dos conceitos psicanalíticos contribuído para o que Hannah Arendt chamou de banalidade do mal? (Arendt, 1964). Ou seja, sobre quais parâmetros a ação educativa distingue o bem do mal, o belo do feio, e como se apresentam essas 
categorias morais, para as crianças e adolescentes, neste novo século? Sobre que ética estão sendo orientados os discursos pedagógicos, quando o sem-sentido dos atos ritualizados substitui a função do pensamento?

Uma nova maneira de gozar aparece com o fato de que hoje se consomem bens que não servem para nada. Não seria pertinente perguntar-se se os inúmeros programas educacionais criados para dar conta do fracasso escolar fracassam porque obedecem a essa lógica?

\section{O QUE SE TRANSMITE NA AÇÃO EDUCATIVA?}

Pergunta-se como o professor pode ser interrogado em sua função, levando-se em consideração que há um certo fracasso em toda transmissão de saber e tendo como pano de fundo esses novos paradigmas.

Uma escola na Zona Sul do Rio apresenta-se bem equipada, com profissionais que, no mínimo, desejam fazer alguma coisa pelas crianças. Esses profissionais demonstram uma necessidade imensa de escuta, fato constatado pelo analista ao indagar de um professor alguns dados sobre as crianças. Só conseguiu colher informações sobre a subjetividade do entrevistado. Outro professor declarou que uma de suas maiores dificuldades foi ensinar em uma turma com defasagens na aprendizagem, pois seus alunos tinham as mais diferentes patologias. Nivelar todos os alunos num único grupo - crianças que não sabiam ler com outras que sabiam - atrapalhou bastante o resultado esperado, mesmo que um arrojado método e um rico material se encontrasse disponivel.

Parece que Freud, já em 1916, vislumbrava que havia um certo saber sobre o inconsciente que não podia ser transmitido, pois este específico saber trazia um núcleo de impossível transmissibilidade, eis, portanto, as dificuldades da psicanálise vinculadas ao ensino. Apesar disso, em sua Conferência XXXIV (Freud, 1932-3; 1908), tocou num ponto precioso para essa questão: "As aplicações da psicanálise são, também, uma confirmação dela". Não estaria Freud aqui indicando o que Lacan iria desenvolver mais tarde com seus textos sobre a psicanálise em extensão? Não estaria também, por meio da importância da psicanálise aplicada, verificando os limites da transmissão? Por outro lado, Freud observou as investigações das crianças que acabavam se transformando em teorias sexuais in- 
fantis (Freud, 1908, p. 211) e verificou que o desejo de saber era para nada saber do que viam. Essa recusa de saber muitas vezes aparecia nas crianças como uma impossibilidade de entrar em contato com temas que tocavam em pontos delicados de sua subjetividade. Os Outros, "os grandes", supostamente sabem: os pais, os professores, o analista, o Estado, mas a criança, ao deparar com a castração desses Outros, desconfia desse saber, e sua descrença, "Unglaube", segundo Freud, alicerça o acesso ao saber através de um conflito.

\section{OS OUTROS DO SABER}

$\mathrm{Na}$ dialética hegeliana, a figura do mestre e do senhor encontra sua verdade no trabalho do escravo, pois um verdadeiro senhor não quer saber de nada, deseja apenas que as coisas andem. O mestre rouba, subtrai o saber do escravo. Lacan (1969), tomando de Hegel essa ambigüidade, a transfere para o uso do significante que pode se definir a partir da clivagem de um significantemestre $\left(S_{1}\right)$, na inscrição dos outros significantes. Trata-se do saber $U_{r}^{2}$ do mestre, característico da matemática, que se produz autônomo. Lacan identificou-o como saber da ciência. Seguindo essa direção, quando algo no saber se produz, cumpre, portanto, função de signi-ficante-mestre. $\mathrm{Na}$ atual política educacional, o que se produz é um não-saber, como pathos político, se for considerado, com Arendt (1999), que o "espaço público" - a escola pública - é "o livre espaço original do político". Uma saída não utópica seria entender por político o âmbito da ação humana atuante e duradoura que se responsabilizasse pelo ato de educar.

O relato de uma professora, que trabalha com crianças apresentando fracasso escolar, dá a medida do que seria responsabilizarse pelo ato de educar. Ela, ao ser questionada sobre o novo método proposto para a alfabetização, diz ser "fora da realidade", e ainda acrescenta que, mesmo assim, consegue adaptá-lo às possibilidades de seus alunos, ou seja, de alguma forma se responsabiliza por seu desejo de saber. A partir de sua experiência anterior com os alunos excepcionais, autorizou-se a trabalhar com os chamados atrasados ou inadaptados à norma. Parece que esta professora trabalha não somente com a norma, mas com a experiência de seu desejo colocado à prova. Partiu, portanto, do princípio de que se deve caminhar acompanhando os passos dos seus caminhantes de acordo com as trilhas ou, quem sabe?, com os trilhamentos do inconsciente, como diz Lacan. Continua a professora: 
"Encontro dificuldades em adaptar o aluno ao novo método. Optei por um método antigo que sempre deu certo: começo a ensinar através da experiência, pela simplicidade, pelo cotidiano, eles vão aprendendo, e assim dá certo".

Parece que essa professora sabe trabalhar com o material infantil, com a expressão de força de acumulação, objeto que constitui a causa do desejo. O capital de libido, na metáfora freudiana do capitalismo, segundo Lacan (1969), demonstra como o objeto "a" pode ocupar o lugar de mais-gozar, como mais-valia, resto que faz girar os discursos, pura perda necessária ao laço social. Neste caso pode-se considerar que a impossibilidade não gerou impotência, porque existiu alguém que não alimentou o sintoma do fracasso escolar, mas o integrou às suas experiências e às das crianças, transformando-o em seu avesso.

A mestria extraída de um sintoma, no caso, uma turma com problemas de aprendizagem, teve uma excelente avaliação. Talvez se possa dizer que foi possível um "saber-fazer" sobre o sexual, com a constatação de que há falta de um significante no Outro $S(\AA)$, ou seja, com o advento da castração na latência, o "ato sexual" é saber ler, escrever e produzir.

\section{O OUTRO DO ESTADO POLÍTICO DEIXA NO AR UMA PERGUNTA: DE QUE SABER SE FAZ A LEI QUE REGE A EDUCAÇÃO?}

O saber como sintoma carrega consigo a verdade que é sempre meia verdade. O lugar do Outro é feito para que nele se inscreva a verdade no jogo da fala e da linguagem. De que verdade fala o discurso político-pedagógico e a que fim serve? A Lei é necessária e por isso tem que ser escrita, entretanto não se apóia na verdade universal. O que garante a Lei tem estatuto de um simulacro (Zizek, 1990, p. 191). Testemunha-se que se está sob a égide das pequenas leis e das normas que regem a aprendizagem. Com Freud, sabe-se que há um fracasso inerente ao próprio princípio do prazer e com Lacan, a partir do Estádio do Espelho, verifica-se que há um engano na formação da imagem constitutiva do corpo. Conclui-se, seguindo esse caminho, que o objeto do conhecimento, modelado à imagem de uma relação especular, resultará sempre insuficiente.

Nesse hiato entre enunciado e enunciação, entre demanda e desejo, pode-se identificar na política o que comporta a dialética 


\section{Dossiê}

do dito que sempre aponta para um outro dizer. É com o "salvese quem puder" que se tem de se virar, no que ele oferece uma mensagem do consumo aqui e agora, do tempo que não tem tempo para compreender e muito menos para concluir. Dessa forma se está sob a égide do instante do olhar, educando em uma época em que o Outro não existe (Miller, 1998b, p. 414). Há uma saída claudicante assegurada pela psicopedagogia: uma posição eclética como uma nova prática que une o psíquico e o pedagógico na educação. Sabe-se, porém, que o ecletismo é uma escola filosófica em sua origem, e, assim, constata-se na psicopedagogia a utilização dos conceitos de L. S. Vigotsky, com sua escola histórico-cultural, em conjugação com a epistemologia genética, de Piaget - uma ação que busca a complementaridade psicopedagógica. Essa via não é, para a psicanálise, uma solução possível. Não se trata de conjugar, mas de extrair conseqüências do enlaçamento da ética da psicanálise com a política da educação. Dessa trama talvez se possa extrair um saber-fazer com o sem-sentido dos sintomas contemporâneos e desatar os chamados "nós cegos" da educação.

\section{REFERÊNCIAS BIBLIOGRÁFICAS}

Arendt, H. (1964). Eichmann em Jerusalém, um relato sobre a banalidade do mal. São Paulo, SP: Companhia das Letras, s.d., $2^{\Perp}$ ed.

(1999). O que é o político. Rio de Janeiro, RJ: Bertrand Brasil, $2^{ \pm}$ed.

Cohen, R. H. P. (1997). 'a' criança brasileira. In Anais do IV Fórum Brasileiro de Psicanálise.

(1998). Novos paradigmas do conceito de sexualidade. In Anais do XV Congresso de Neurologia e Psiquiatria Infantil. Enelivros.

Freud, S. (1908). Sobre as teorias sexuais infantis. In Edição standard brasileiral das obras completas de Sigmund Freud (J. Salomão, trad.) (Vol. 9, p. 211). Rio de Janeiro, RJ: Imago, 1969.

(1919). O estranho. In Edição standard brasileira das obras completas de Sigmund Freud (J. Salomão, trad.) (Vol. 17). Rio de Janeiro, RJ: Imago, 1969.

-(1920-1). Psicologia de grupo e análise do eu. In Edição standard brasileira das obras completas de Sigmund Freud (J. Salomão, trad.) (Vol. 18). Rio de Janeiro, RJ: Imago, 1969.

- (1932-3). Novas conferências introdutórias sobre psicanálise. Conferência XXXIV. In Ediçĩo standard brasileira das obras completas de Sigmund Freud (J. Salomão, trad.) (Vol. 22). Rio de Janeiro, RJ: Imago, 1969.

Lacan, J. (1969). O seminário, Livro XVII, O avesso da psicanálise. Rio de Janeiro, RJ: Jorge Zahar, s.d.

-_-_(1972-3). O seminário, Livro XX, Mais ainda. Rio de Janeiro, RJ: Jorge Zahar, 1975. 
Martin, H.-P. \& Shumann, H. (1997). A armadilha da globalização, o assalto à democracia e ao bem-estar social. São Paulo, SP: Globo.

Miller, J. A. (1998a). O osso de uma análise. Revista da EBP.

-_-_- (1998b). Los signos del goce (G. Brodsky, trad. e transcr.). Buenos Aires/ Barcelona/México: Paidós.

---_- (1999). La psychose ordinaire. La Convention d'Antibes. Paris: Agalma/Le Seuil, inédito.

Miller, J.-A. \& Laurent, E. (1997). Goces sin otro. In Gorali, V. (compilaçāo). Estudios de anorexia y bulimia. Rio de Janeiro, RJ: Biblioteca EBP, mimeo.

Zizek, S. (1990). Eles não sabem o que fazem. O sublime objeto da ideologia. Rio de Janeiro, RJ: Jorge Zahar, 1992.

\section{NOTAS}

1 Citaçōes de professores da Rede Municipal do Rio de Janeiro.

2 Referência ao Urverdrängt - "que quer dizer justamente aquilo que não teve de ser recalcado porque já o está desde a origem" (Lacan, 1969, p. 84).

Recebido em novembro/2001. 